\title{
Therapy of X-Linked Adrenoleukodystrophy
}

\author{
Hugo W. Moser, M.D
}

\begin{abstract}
Summary: Current therapies for X-linked adrenoleukodystrophy (X-ALD) include replacement therapy with adrenal steroids, which is mandatory for all patients with impaired adrenal function but does not alter neurological progression significantly; dietary therapy with "Lorenzo's Oil," which appears to have a preventive effect in asymptomatic boys whose brain MRI is normal; and hematopoietic stem cell transplantation in patients in the early stage of the cerebral inflammatory pheno-
\end{abstract}

type. Application of these interventions requires careful assessment of the patients' phenotype, which often changes over time. Family screening provides important opportunities for disease prevention. Key Words: Adrenoleukodystrophy, adrenomyeloneuropathy, adrenal insufficiency, bone marrow transplant, very long chain fatty acids, peroxisomal disorders, neonatal screening.

\section{INTRODUCTION}

$\mathrm{X}$-linked adrenoleukodystrophy (X-ALD) is caused by a defect in the gene ABCD1 that maps to Xq 28 and codes for ALDP, a peroxisomal membrane protein. ${ }^{1,2}$ ALDP is a member of the ATP-binding cassette (ABC) transporter superfamily. ${ }^{3}$ For reasons that are not yet understood this defect leads to the accumulation of saturated very long chain fatty acids (VLCFA) such as hexacosanoic acid (C26:0) in the adrenal gland and nervous system white matter ${ }^{4}$ and other tissues and in plasma. $^{5}$ The VLCFA excess appears to be due to their impaired degradation, ${ }^{5,6}$ a reaction that normally takes place in the peroxisome, ${ }^{7}$ although recent studies indicate that the defects in fatty acid metabolism are complex and not yet fully understood. ${ }^{8}$ Demonstration of excess of VLCFA in plasma is the most commonly used diagnostic assay. ${ }^{5}$ The VLCFA excess may also contribute to pathogenesis. ${ }^{9}$ The mode of inheritance is X-linked. Males are affected most severely, but approximately $50 \%$ of women heterozygous for X-ALD develop some neurological deficits in middle age or later. ${ }^{10,11}$ The incidence in males is estimated to be 1:21,000, and 1:14,000 in females. ${ }^{12}$ All ethnic groups are affected without apparent predilection for any one group. More than 500 different mutations in the ABCD1 gene have been described in X-ALD patients, ${ }^{13}$ and are updated in the website http://www.X-ald.nl). Demonstration of a

Director of Neurogenetics Research, Kennedy Krieger Institute, Professor of Neurology and Pediatrics, Johns Hopkins University, 707 North Broadway, Baltimore, MD 21205. E-Mail: moser@kennedykrieger.org characteristic pattern of increase in the levels of VLCFA in plasma is a reliable method for confirming the diagnosis in males; these levels are already increased at birth. ${ }^{5}$ False negative results with the plasma VLCFA assay occur in 15 to $20 \%$ of women heterozygous for $\mathrm{X}-\mathrm{ALD}$, and mutation analysis is required for the definitive identification of carriers. ${ }^{14} \mathrm{X}$-ALD must be distinguished sharply from neonatal adrenoleukodystrophy, which has an entirely different phenotype, biochemical and genetic basis and an autosomal recessive mode of inheritance. $^{15}$

\section{PHENOTYPES}

\section{Phenotypes in X-ALD males}

Cerebral inflammatory forms. Approximately 50\% of patients with the genetic defect of X-ALD develop the inflammatory cerebral form at some time in their life. The childhood cerebral phenotype is the one described initially by Siemerling and Creutzfeldt, ${ }^{16}$ and until 1976 was considered to be essentially the only phenotype. It is associated with an intensely inflammatory demyelination that involves the cerebral hemispheres mainly. In approximately $85 \%$ of the patients the initial and most severe lesion involves the parieto-occipital regions and spreads rostrally. ${ }^{17}$ In approximately $15 \%$ the initial lesion involves the frontal lobes. ${ }^{18}$ Intense perivascular infiltration with lymphocytes is a key feature which was emphasized by Paul Schilder, ${ }^{19}$ whose name was attached originally to the disorder. The perivascular lymphocytes are mainly CD8 cytotoxic t-lymphocytes. This inflammatory response is a characteristic feature of this 
form of X-ALD, and leads to cytolysis of oligodendrocytes. The action of inflammatory cytokines has been demonstrated and autoimmume mechanisms that involve CD1-mediated lipid antigen presentation have been proposed. $^{20,21}$ The abnormal accumulation of VLCFA in brain white matter is thought to play a role in the myelin and axon destructive cascade that occurs in the cerebral forms of X-ALD. ${ }^{21,22}$ The symmetrical parieto-occipital or frontal location lesions are associated with breakdown of the blood brain barrier and accumulation of contrast material leads to rather characteristic brain MRI abnormalities. ${ }^{18,23}$ Loes et al. ${ }^{24}$ developed a frequently used system for grading the degree of MRI abnormality in $\mathrm{X}$-ALD. Abnormalities in MR spectroscopy precede changes demonstrable by conventional MRI. ${ }^{25,26}$

The cerebral forms of X-ALD present most commonly in childhood between four and eight years of age. Early development is entirely normal, with normal neurological development, cognitive function and normal brain MRI. ${ }^{27}$ Brain MRI abnormalities precede symptoms. ${ }^{28}$ In our experience, 21 months is the earliest age of clinical manifestations. Onset prior to 3 years of age is rare. The initial manifestations resemble those of attention deficit hyperactivity disorder (ADHD) or psychological disorder. Other common initial symptoms are defects in auditory discrimination or visual processing, impaired spatial coordination, poor handwriting, impaired memory, declining school performance and occasionally seizures. The illness advances rapidly and often leads to severe neurological disability within two to three years with death at varying intervals thereafter. Adrenal insufficiency is often the initial manifestation of X-ALD and more than $70 \%$ of patients have primary adrenocortical insufficiency.

The initial manifestations of the cerebral forms may also occur in adolescence and adulthood, but for unknown reasons the susceptibility for the inflammatory cerebral phenotype diminishes with age. ${ }^{28-30}$ The risk for developing the inflammatory cerebral phenotype diminishes substantially in neurologically asymptomatically boys whose brain MRI remains normal until 7 years of age. ${ }^{30}$

\section{Adrenomyeloneuropathy (AMN)}

In our experience virtually all males with the gene abnormality develop some type of neurological abnormality during their life span. Approximately $45 \%$ develop the adrenomyeloneuropathy (AMN) phenotype. AMN presents as a slowly progressive spastic paraparesis with sensory and sphincter disturbances in young adults, often without evidence of brain dysfunction. ${ }^{31}$ The link between AMN and the cerebral forms of XALD was recognized concurrently and independently in 1976 by Griffin and associates in the USA ${ }^{32}$ and Budka and associates in Vienna. ${ }^{33}$ Powers and associates have conducted extensive studies of the pathology of AMN, and have demonstrated that it is a non-inflammatory distal axonopathy. ${ }^{34-36}$ The distal axonopathy affects most severely the dorsal columns in the cervical cord segments and the corticospinal tracts in the lower thoracic and lumbar segments of the spinal cord. Evidence of axonopathy is also present in the peripheral nervous system. ${ }^{37}$ In AMN the primary defect is in the axon, with little or no evidence of an inflammatory response, with myelin loss a consequence to this, and thus differs fundamentally from the cerebral inflammatory forms of XALD. X-ALD patients in whom neurological involvement is confined to the spinal cord and peripheral nerves and who do not have clinical or MRI evidence of brain involvement are referred to as having the pure AMN phenotype. On MRI they do not show evidence of inflammatory brain involvement although they may show abnormalities of the corticospinal tract in the internal capsule. ${ }^{18,38}$ Brain Magnetic Resonance Spectroscopy studies show evidence of axonal involvement. ${ }^{39}$ Magnetic Resonance transfer MRI permits quantitation of the abnormalities in the dorsal columns of the cervical cord. $^{40}$

AMN and the cerebral forms of X-ALD often co-occur in the same family. There is no correlation between the nature of the ABCD1 mutation and phenotype. The action of a modifier gene has been proposed. ${ }^{41}$ Currently, it is not possible to determine whether a young asymptomatic male is at risk for AMN or the cerebral phenotype. Approximately 20\% of patients with AMN also have or develop clinical and MRI evidence of inflammatory brain disease. ${ }^{42}$ Such patients are classified as having the AMN cerebral phenotype. They progress more rapidly than those with the pure AMN phenotype.

\section{The "Addison-only phenotype"}

Approximately $20 \%$ of male X-ALD patients have primary adrenocortical insufficiency without clinical or MRI evidence of neurological involvement. Such patients are classified as the "Addison only" pheno type of X-ALD. They cannot be distinguished clinically from patients in whom Addison disease is due to other causes. It has been estimated that up to $30 \%$ of idiopathic disease in young boys is due to X-ALD. ${ }^{43,44}$ Addison only XALD patients are identified by screening patients with Addison disease with plasma VLCFA. We recommend that this assay be performed in all male patients with Addison disease. Adrenal function tests performed in asymptomatic boys identified by VLCFA screening of relatives of known X-ALD patients, have revealed that in $70 \%$ the plasma ACTH levels were already increased before age two years, indicative of impaired adrenal reserve. ${ }^{45}$ Careful monitoring and appropriate adrenal hormone replacement therapy can thus prevent the morbidity and mortality associated with overt adrenal insuf- 
ficiency. Nearly all patients with the "Addison only" phenotype caused by ALD, later also develop either the cerebral or the AMN neurological manifestations. Careful monitoring of their neurological status is required so that they receive appropriate interventions.

\section{"The asymptomatic-normal MRI" phenotype}

Plasma VLCFA screening of both the immediate and extended family of known X-ALD patients has led to the identification of more than 200 males who have the biochemical and gene abnormality of X-ALD, but who are free of symptoms or neurological abnormalities and normal conventional brain MRI ${ }^{12}$ (even though Magnetic Resonance Spectroscopy studies may show subtle changes). ${ }^{26,46}$ It is likely that this will become one of the most frequent XALD phenotypes. Most of the patients in this category are less than seven years old. Cognitive function is normal in most, ${ }^{27}$ and thus provide a key group for therapeutic interventions. Longer follow-up is required to assess long-term prognosis. While the risk of developing the cerebral inflammatory phenotype diminishes after 7 years, our previous experience suggests that they are at high risk of developing AMN in adulthood.

\section{Clinical manifestations in women who are heterozygous for $\mathrm{X}$-ALD}

Approximately half of women who are heterozygous for X-ALD develop an AMN-like syndrome in middle age or later. ${ }^{10,47}$ It is of later onset and milder than the AMN that affects males, but a small proportion of neurologically symptomatic women require a wheelchair. Overt adrenal insufficiency and the inflammatory cerebral phenotype occur in approximately $1 \%$ of heterozygotes. ${ }^{48}$ In one instance the severe phenotype in an ALD heterozygote was shown to be due to an Xq27-Ter deletion in the second X-chromosome. ${ }^{49}$ Skewed X-chromosome inactivation patterns have been proposed as the cause of neurological involvement in the symptomatic carriers. ${ }^{50,51}$

\section{THERAPY}

General supportive care and symptomatic treatment for patient and family, provided by pediatrician or neurologist, with appropriate specialist consultation, nursing, schools, rehabilitation and social agencies, are the cornerstones for the care and treatment of patients with X-ALD. Currently used medical therapies of X-ALD include hormone replacement therapy, dietary therapy with "Lorenzo's Oil," and Hematopoetic Stem Cell Transplantation. Other approaches are still under investigation. These include phenylbutyrate, which has shown promising results in a mouse model of X-ALD, ${ }^{52}$ arginine butyrate, ${ }^{53}$ and Lovastatin. ${ }^{54}$ Particular interest attaches to approaches that increase the expression of $\mathrm{ABCD} 2,{ }^{55}$ a gene that maps to chromosome 12 and codes for a protein that can substitute in part for the function of ALDP, and in the long range, gene replacement therapy. ${ }^{56}$

\section{Hormone replacement therapy}

Adrenal hormone replacement therapy is mandatory for all X-ALD patients who have primary adrenocortical insufficiency, which is present in more than $70 \%$ of male X-ALD patients. It can be life saving. All male patients should be monitored for adrenal insufficiency with plasma ACTH levels and, when ambiguous, with the ACTH stimulation test. Baseline cortisol levels are not sufficiently sensitive. ${ }^{45}$ While the hormone replacement benefits the endocrine status and improves general strength and well-being, it does not appear to alter neurological status significantly, although some moderate benefit has been reported in AMN. ${ }^{57}$ Glucocorticoid requirements are generally the same as those used for other forms of primary adrenal insufficiency. Adult patients generally receive $25 \mathrm{mg}$ of cortisone acetate or $20 \mathrm{mg}$ hydrocortisone administered in the early morning with a smaller second dose of $12.5 \mathrm{mg}$ or $10 \mathrm{mg}$ respectively, given in the late afternoon. The dosage in children is 5 to $10 \mathrm{mg} / 24 \mathrm{hr}$. Patients are instructed in a protocol to augment glucocorticoid coverage during physical and mental stress and provided with a parental methylprednisolone dose for use if vomiting prevents oral dosing. When postural hypotension, hyponatremia or hyperkalemia persist despite adequate glucocorticoid replacement, fludrocortisone 0.05 to $0.1 \mathrm{mg} / \mathrm{day}$, is prescribed. Males with clinical manifestations of hypogonadism that are associated with low serum testosterone concentration should receive androgens.

\section{Dietary therapy with "Lorenzo's Oil"}

Lorenzo's Oil (LO) is a 4:1 mixture of glyceryl trioleate and glyceryl trierucate. Oral administration of this oil, combined with moderate reduction of fat, normalizes or significantly lowers the levels of VLCFA in the plasma of patients with X-ALD within four weeks. ${ }^{58}$ This striking biochemical effect engendered the hope that this would have a favorable effect on clinical course, but a series of single-arm clinical trials led to the consensus that the oil did not significantly alter the rate of progression who were already symptomatic when therapy was initiated, particularly those with the cerebral inflammatory phenotypes. ${ }^{59-62}$ However, two recent reports provide evidence that LO may benefit two phenotypes: a preventive effect in asymptomatic boys whose brain MRI is normal ${ }^{28}$ and a slowing of progression of pure AMN. ${ }^{63}$

The prevention study involved 89 asymptomatic patients with normal MRI, baseline age $4.7 \pm 4.1$ years who were followed for $6.9 \pm 2.7$ years. A proportional hazards model was used to evaluate the association between reduction of plasma VLCFA levels and the devel- 
opment of abnormal MRI and neurological abnormalities, and a statistically significant association was demonstrated. The data indicate that substantial and consistent reduction of plasma C26:0 levels led to a two-fold reduction or greater reduction of the risk of developing the childhood cerebral form of X-ALD without serious adverse effects and maintenance of normal cognitive development and physical growth. The dietary therapy requires careful supervision by a multidisciplinary team including a nutritionist to ensure that VLCFA levels are lowered, and that nutritional balance is maintained. There is a moderate reduction of platelet count in approximately $30 \%$ of patients, but this can be managed by adjustment of LO dosage. Abnormal bleeding was not observed. Adrenal function must be monitored and appropriate adrenal hormone replacement provided. Brain MRI is monitored at 6 to 12 months intervals. If MRI abnormalities develop, patients are considered for Hematopoietic Stem Cell Transplantation (HSCT) in accordance with current criteria. ${ }^{64}$ The authors recommend that carefully supervised LO therapy be offered to asymptomatic boys with normal brain MRI whose age is between one and eight years, the age period of greatest risk for the development of the childhood cerebral phenotype.

Koehler and Sokolowski have conducted an open study of the effects of LO on the neurological progression in men with pure AMN. ${ }^{63}$ The study included 45 men. The patients were followed for a period of 6.3 years (range 2-12.8 years). All of the patients normalized their plasma VLCFA levels. Twenty-two (48\%) remained absolutely stable and in $84 \%$ progression during therapy was significantly slower than it had been during the pre-treatment period. While these results are highly encouraging, definitive conclusion is not possible because of the open study design. A double-blinded placebocontrolled study of LO therapy in men and women with pure AMN is now in progress at the Kennedy Krieger Institute.

\section{Hematopoietic Stem Cell Transplantation (HSCT)}

In 1990 Aubourg et al. ${ }^{65}$ reported stabilization (and possibly reversal) of neurological changes in a boy with early childhood cerebral ALD. Shapiro et al. ${ }^{66}$ reported that this stabilization persists for five to ten years. The mechanisms of the benefit of HSCT has not been defined. Donor derived cells do enter the central nervous system and the gradual replacement of a portion of perivascular microglia by donor derived cells, ${ }^{67,68}$ may exert a favorable metabolic effect. Alternatively or in addition the favorable effect may be due to the immunosuppression and the reconstitution of the immune system by donor derived celles, affect HSCT. The immunosuppression alone apparently does not account for this effect, because patients who were immunosuppressed, but did not en- graft, continued to progress. ${ }^{69}$ Peters et al. ${ }^{64}$ have reported the follow-up of 126 patients with X-ALD who had received either bone marrow or umbilical cord HSCT during the period 1981-1999. Mahmood et al. ${ }^{70}$ compared the outcome in the transplanted group with a comparable group of patients who were followed at the Kennedy Krieger Institute who had not been transplanted. Outcome of the transplant varied strikingly with the clinical stage of the illness at the time of transplant. Outcome was favorable in patients in whom transplant was performed at the early stage of the illness, defined here as those patients in whom neurological deficits were confined to one or less of six neurological domains, the 34-point Loes ALD MRI severity score ${ }^{24}$ was $<9$, and the performance IQ was $>80$. In this group the five-year survival was $92 \%$ and the neurological and functional status far superior to that in the non-transplanted group. For the group with more advanced deficits, five-year survival for the transplant group (45\%) was less than that in the non-transplant group (60\%). HSCT is recommended strongly for patients in the early stage of cerebral X-ALD, but not for those in the more advanced stages. It is not yet known whether HSCT can benefit patients with the non-inflammatory pure AMN. Such trials have not been performed because in view of the risk of HSCT and the slow progression of pure AMN, the risk benefit ratio for such patients did not favor transplant. However, it may be possible to assess the potential benefit of HSCT for pure AMN by determining whether boys who were transplanted for the cerebral ALD develop AMN in early adulthood. At this time, we do not recommend HSCT for asymptomatic patients who have a normal MRI. This recommendation is based upon the risk of the procedure and the past experience which indicates that half of these patients are not expected to develop the cerebral ALD even without therapy. However, this recommendation may be changed if HSCT is later found to benefit patients with pure AMN and if the risk of HSCT can be diminished.

\section{Therapeutic approaches for specific X-ALD phenotypes}

Table 1 summarizes the therapeutic approaches to specific ALD phenotypes.

The following points are emphasized:

1) Our study of more than one thousand pedigrees with X-ALD indicates that all affected males develop either adrenal or neurological disability, and most commonly both, during their lifetime. Diagnosis and therapy is therefore important.

2) Adrenal function must be monitored in all males, and appropriate replacement therapy be provided when there is clinical or biochemical evidence of primary adrenocortical insufficiency. Continued 
TABLE 1. X-Linked Adrenoleukodystrophy Phenotypes

\begin{tabular}{|c|c|c|c|}
\hline Phenotype Males**** & $\begin{array}{l}\text { Age (years) of } \\
\text { Presentation }\end{array}$ & Follow-up Tests & Recommended Therapy \\
\hline Asymptomatic - MRI normal & $0-10+$ & $\begin{array}{l}\text { Monitor MRI and adrenal function. } \\
\text { Family screening }\end{array}$ & Lorenzo's oil, ${ }^{28}$ adrenal $\mathrm{Rx}$ \\
\hline $\begin{array}{l}\text { Asymptomatic - MRI } \\
\text { abnormal }\end{array}$ & $2-10+$ & $\begin{array}{l}\text { Neurological and neuro- } \\
\text { psychological test, adrenal } \\
\text { function }\end{array}$ & $\mathrm{HSCT}^{64}{ }^{64}$ adrenal Rx \\
\hline Addison only - MRI normal & $0-10+$ & $\begin{array}{l}\text { Monitor MRI. Neurological and } \\
\text { neuropsychological test. }\end{array}$ & Lorenzo's oil, ${ }^{28}$ adrenal $\mathrm{Rx}$ \\
\hline $\begin{array}{l}\text { Addison only - MRI } \\
\text { abnormal }\end{array}$ & $0-10+$ & $\begin{array}{l}\text { Neurological and } \\
\text { neuropsychological test, MRS }\end{array}$ & HSCT $^{64}$ adrenal Rx \\
\hline $\begin{array}{l}\text { Cerebral - mild* without } \\
\text { AMN }^{28}\end{array}$ & $\begin{array}{l}3-10 \text { common } \\
11-21 \text { intermed } \\
21+\text { rare }\end{array}$ & $\begin{array}{l}\text { Neurological and } \\
\text { neuropsychological test, family } \\
\text { screening, adrenal function }\end{array}$ & $\mathrm{HSCT}^{64}$ adrenal Rx \\
\hline $\begin{array}{l}\text { Cerebral - advanced* without } \\
\text { AMN }^{28}\end{array}$ & 5-adulthood & $\begin{array}{l}\text { Adrenal function, neurological and } \\
\text { neuropsychological test, family } \\
\text { screening }\end{array}$ & $\begin{array}{l}\text { Adrenal Rx, } \\
\text { ?immunosuppression } \\
\text { General support }\end{array}$ \\
\hline AMN pure $* * 23$ & $28 \pm 9(\mathrm{SD})$ & $\begin{array}{l}\text { Brain MRI, adrenal function, MTS, } \\
\text { SSEP, family screening }\end{array}$ & $\begin{array}{l}\text { Adrenal Rx, ?Lorenzo's } \\
\text { oil***, physical therapy }\end{array}$ \\
\hline AMN cerebral $* * 23$ & $28 \pm 9(\mathrm{SD})$ & $\begin{array}{l}\text { As in pure AMN plus neurological } \\
\text { and neuropsychological test, } \\
\text { EEG, psychiatry, family } \\
\text { screening }\end{array}$ & $\begin{array}{l}\text { Adrenal Rx, general } \\
\text { support, ?HSCT***** } \\
\text { ?immunosuppression }\end{array}$ \\
\hline \multicolumn{4}{|l|}{ Phenotype Female } \\
\hline $\begin{array}{l}\text { Asymptomatic - neuro } \\
\text { normal }\end{array}$ & Any age & $\begin{array}{l}\text { Neuro exam and adrenal function, } \\
\text { monitor MRI, family screening }\end{array}$ & $\begin{array}{l}\text { Genetic counseling, general } \\
\text { support }\end{array}$ \\
\hline $\begin{array}{l}\text { Heterozygotes - symptoms or } \\
\text { neuro abnormalities }\end{array}$ & Rare below age 30 & $\begin{array}{l}\text { Adrenal function, MTS, SSEP, } \\
\text { family screening }\end{array}$ & $\begin{array}{l}\text { Genetic counseling, physical } \\
\text { therapy, adrenal Rx, } \\
\text { ?Lorenzo's oil***, general } \\
\text { support }\end{array}$ \\
\hline
\end{tabular}

$\mathrm{ADHD}=$ Attention Deficit Hyperactivity Disorder; Adrenal Rx $=$ (Adrenal hormone replacement therapy when adrenal function is impaired); ALS = Amyotrophic lateral sclerosis; DNA = ABCD1 mutation analysis ${ }^{48}$; HSCT $=$ Hematopoietic stem cell transplant ${ }^{64}$; MRI $=$ Magnetic Resonance Imaging; MTS = Magnetization Transfer MRI cervical cord ${ }^{40}$; SSEP $=$ Somatosensory evoked potentials; VLCFA $=$ Very long chain fatty acids assay in plasma ${ }^{5}$

Modified from Moser HW and Raymond GV, Adrenoleukodystrophy: New Approaches to a Neurodegenerative Disease. JAMA in press, 2005. * See reference ${ }^{64}$ for distinction between mild and severe cerebral forms. ** See text for distinction between pure and cerebral AMN. *** Placebo controlled trial in progress. **** False negatives occur. ***** HSCT being considered for mild AMN cerebral.

vigilance about this aspect is necessary, particularly in boys who present with behavioral disturbances and in adult AMN patients who live independently at times of physical stress.

3) All male patients with Addison disease should be screened for ALD with the plasma VLCFA assay, because without treatment nearly all will later develop neurological deficits.

4) Current therapies for cerebral ALD, that is dietary therapy and HSCT, are beneficial only in patients who are asymptomatic or in the early stage of the illness. More than half of the patients with cerebral involvement who are diagnosed on the basis of symptoms are too advanced to benefit from currently available therapies.

In his report on the international experience with HSCT for boys with cerebral X-ALD, Peters pointed out that approximately one third of the cohort were diagnosed on the basis of a positive family history while the remaining two-thirds of patients in the cohort were diagnosed on the basis of signs and symptoms of cerebral X-ALD. There were marked differences with respect to outcomes between these two groups. Specifically, boys who were diagnosed at an early stage of cerebral disease, typically because of a positive family history, enjoyed a statistically significantly higher probability of survival at 5 years and a markedly superior quality of life with respect to neurologic and neuropsychologic function when compared to boys with advanced cerebral X-ALD. ${ }^{64}$ Emphasis should therefore be on diagnosis before neurological symptoms occur. At present this is achieved by screening at-risk relatives (including the extended family) of all known X-ALD patients. (It should be recalled that only $5 \%$ of ALD patients have de-novo mutations. ${ }^{12}$ ) Screening of Addison disease patients with the plasma VLCFA assay provides another method to identify to neurologically asymptomatic patients. Methods to develop and 
validate neonatal screening are in progress, and if this can be achieved and implemented, this would permit monitoring adrenal function and brain MRI in all patients, and permit prevention of overt Addison disease due to ALD, and timely HSCT therapy of patients with cerebral involvement.

While early diagnosis and application of current therapies has improved the prognosis of patients with $\mathrm{X}$ ALD, there is need to gain better understanding of pathogenesis and new and more effective therapies.

\section{PREVENTION}

Even though current therapies show promise, they carry a risk, their long-term efficacy is not proven and they place considerable and at times very severe burdens on the patients and their families. Prevention, therefore, continues to be top priority. This can be achieved through genetic counseling. Mutation analysis permits reliable identification of women who are heterozygous for $\mathrm{X}-\mathrm{ALD}^{14}$ and should be offered to all women who are at risk. Prenatal diagnosis that combines biochemical, immunological and DNA analysis is reliable. ${ }^{71}$ Preimplantation diagnosis, which is now available, offers an additional alternative.

Acknowledgments: This work was supported by Grant 685008 from the Office of Orphan Drug Products of the Food and Drug Administration, Rockville, MD, the Johns Hopkins University School of Medicine General Clinical Research Center grant MO-1-R00052 from the National Center for Research Resources/National Institute of Health, Bethesda, MD, grants HD 10981 and HD 39276 from the National Institutes of Health, Bethesda, MD, and grants from the Myelin Project, Dunn Loring, MD, and the United Leukodystrophy Foundation, Sycamore, IL.

\section{REFERENCES}

1. Moser HW, Smith KD, Watkins PA, Powers J, Moser AB. Xlinked adrenoleukodystrophy, in Scriver CR, Beaudet AL, Sly WS, Valle D (eds): The Metabolic and Molecular Bases of Inherited Disease. New York, McGraw Hill, 2001, pp. 3257-3301.

2. Mosser J, Douar AM, Sarde CO, Kioschis P, Feil R, Moser H, Poustka AM, Mandel JL, Aubourg P. Putative X-linked adrenoleukodystrophy gene shares unexpected homology with ABC transporters. Nature 361:726-730, 1993.

3. Dean M, Hamon Y, Chimini G. The human ATP-binding cassette (ABC) transporter superfamily. J Lipid Res 42:1007-1017, 2001.

4. Igarashi M, Schaumburg HH, Powers J, Kishmoto Y, Kolodny E, Suzuki K. Fatty acid abnormality in adrenoleukodystrophy. J Neurochem 26:851-860, 1976.

5. Moser AB, Kreiter N, Bezman L, Lu S, Raymond GV, Naidu S, Moser HW. Plasma very long chain fatty acids in 3,000 peroxisome disease patients and 29,000 controls. Ann Neurol 45:100110, 1999.

6. Lazo O, Contreras M, Hashmi M, Stanley W, Irazu C, Singh I. Peroxisomal lignoceroyl-CoA ligase deficiency in childhood adrenoleukodystrophy and adrenomyeloneuropathy. Proc Natl Acad Sci U S A 85:7647-7651, 1988.

7. Singh I, Moser AE, Goldfischer S, Moser HW. Lignoceric acid is oxidized in the peroxisome: implications for the Zellweger cere- bro-hepato-renal syndrome and adrenoleukodystrophy. Proc Natl Acad Sci U S A 81:4203-4207, 1984.

8. McGuinness MC, Lu JF, Zhang HP, Dong GX, Heinzer AK, Watkins PA, Powers J, Smith KD. Role of ALDP (ABCD1) and mitochondria in X-linked adrenoleukodystrophy. Mol Cell Biol 23:744-53, 2003.

9. Ho JK, Moser H, Kishimoto Y, Hamilton JA. Interactions of a very long chain fatty acid with model membranes and serum albumin. Implications for the pathogenesis of adrenoleukodystrophy. J Clin Invest 96:1455-1463, 1995.

10. Moser HW, Moser AB, Naidu S, Bergin A. Clinical aspects of adrenoleukodystrophy and adrenomyeloneuropathy. Dev Neurosci 13:254-261, 1991.

11. Restuccia D, Di Lazzaro V, Valeriani M, Oliviero A, Le Pera D, Barba C, Cappa M, Bertini E, Di Capua M, Tonali P. Neurophysiologic follow-up of long-term dietary treatment in adult- onset adrenoleukodystrophy. Neurology 52:810-816, 1999.

12. Bezman L, Moser AB, Raymond GV, Rinaldo P, Watkins PA, Smith KD, Kass NE, Moser HW. Adrenoleukodystrophy: incidence, new mutation rate, and results of extended family screening. Ann Neurol 49:512-517, 2001.

13. Kemp S, Pujol A, Waterham HR, van Geel BM, Boehm CD, Raymond GV, Cutting GR, Wanders RJ, Moser HW. ABCD1 mutations and the $\mathrm{X}$-linked adrenoleukodystrophy mutation database: role in diagnosis and clinical correlations. Hum Mutat 18: 499-515, 2001.

14. Boehm CD, Cutting GR, Lachtermacher MB, Moser HW, Chong SS. Accurate DNA-based diagnostic and carrier testing for Xlinked adrenoleukodystrophy. Mol Genet Metab 66:128-136, 1999.

15. Kelley RI, Datta NS, Dobyns WB, Hajra AK, Moser AB, Noetzel MJ, Zackai EH, Moser HW. Neonatal adrenoleukodystrophy: new cases, biochemical studies, and differentiation from Zellweger and related peroxisomal polydystrophy syndromes. Am J Med Genet 23:869-901, 1986.

16. Siemerling E, Creutzfeldt HG. Bronzekrankheit und Sklerosierende Encephalomyelitis. Arch Psychiatr Nervenkr 68:217-244, 1923.

17. Schaumburg HH, Powers JM, Raine CS, Suzuki K, Richardson EP Jr. Adrenoleukodystrophy. A clinical and pathological study of 17 cases. Arch Neurol 32:577-591, 1975.

18. Loes DJ, Fatemi A, Melhem ER, Gupte N, Bezman L, Moser HW, Raymond GV. Analysis of MRI patterns aids prediction of progression in X-linked adrenoleukodystrophy. Neurology 61:369374, 2003.

19. Schilder P. Zur Frage der Encephalitis Periaxialis Diffusa (Sogenannet Diffuse Sklerose). Neur Psych 15:359-376, 1913.

20. Powers JM, Liu Y, Moser AB, Moser HW. The inflammatory myelinopathy of adreno-leukodystrophy: cells, effector molecules, and pathogenetic implications. J Neuropathol Exp Neurol 51:630643, 1992.

21. Ito M, Blumberg BM, Mock DJ, Goodman AD, Moser AB, Moser HW, Smith KD, Powers JM. Potential environmental and host participants in the early white matter lesion of adreno-leukodystrophy: morphologic evidence for CD8 cytotoxic T cells, cytolysis of oligodendrocytes, and CD1-mediated lipid antigen presentation. J Neuropathol Exp Neurol 60:1004-1019, 2001.

22. Paintlia AS, Gilg AG, Khan M, Singh AK, Barbosa E, Singh I. Correlation of very long chain fatty acids accumulation and inflammatory disease progression in childhood ALD: Implications for potential therapies. Neurobiol Dis 14:425-439, 2003.

23. Kumar AJ, Rosenbaum AE, Naidu S, Wenger L, Citrin CM, Lindenberg R, Kim WS, Zinreich SJ, Molliver ME, Mayberg HS, Moser HW. Adrenoleukodystrophy: correlating MR imaging with CT. Radiology 165:497-504, 1987.

24. Loes DJ, Hite S, Moser H, Stillman AE, Shapiro E, Lockman L, Latchaw RE, Krivit W. Adrenoleukodystrophy: a scoring method for brain MR observations. AJNR Am J Neuroradiol 15:17611766, 1994.

25. Eichler FS, Itoh R, Barker PB, Mori S, Garrett ES, van Zijl PC, Moser HW, Raymond GV, Melhem ER. Proton MR spectroscopic and diffusion tensor brain MR imaging in X- linked adrenoleukodystrophy: initial experience. Radiology 225:245-252, 2002. 
26. Oz G, Tkac I, Charnas LR, Choi IY, Bjoraker KJ, Shapiro EG, Gruetter R. Assessment of adrenoleukodystrophy lesions by high field MRS in non-sedated pediatric patients. Neurology 64:434441, 2005.

27. Cox C, Dubey P, Raymond GV, Mahmood A, Moser AB, Moser HW. Cognitive evaluation of neurologically asymptomatic boys with X-linked adrenoleukodystrophy. Arch Neurol in press, 2005.

28. Moser HW, Raymond GV, Lu SE, Muenz LR, Moser AB, Xu J, Jones RO, Loes DJ, Melhem ER, Dubey P, Bezman L, Brereton $\mathrm{NH}$, Odone A. Follow-up of 89 Lorenzo's Oil treated asymptomatic adrenoleukodystrophy patients. Arch Neurol 62:1073-1080, 2005.

29. Moser HW, Moser AB, Smith KD, Bergin A, Borel J, Shankroff J, Stine OC, Merette C, Ott J, Krivit W, Shapiro E. Adrenoleukodystrophy: phenotypic variability and implications for therapy. J Inherit Metab Dis 15:645-664, 1992.

30. Moser HW, Loes DJ, Melhem ER, Raymond GV, Bezman L, Cox CS, Lu SE. X-Linked adrenoleukodystrophy: overview and prognosis as a function of age and brain magnetic resonance imaging abnormality. A study involving 372 patients. Neuropediatrics 31 : 227-239, 2000.

31. Edwin D, Speedie LJ, Kohler W, Naidu S, Kruse B, Moser HW. Cognitive and brain magnetic resonance imaging findings in adrenomyeloneuropathy. Ann Neurol 40:675-678, 1996.

32. Griffin JW, Goren E, Schaumburg H, Engel WK, Loriaux L. Adrenomyeloneuropathy: a probable variant of adrenoleukodystrophy. I. Clinical and endocrinologic aspects. Neurology 27:11071113,1977

33. Budka H, Sluga E, Heiss WD. Spastic paraplegia associated with Addison's disease: adult variant of adreno-leukodystrophy. J Neurol 213:237-250, 1976.

34. Powers JM. Adreno-leukodystrophy (adreno-testiculo-leukomyelo-neuropathic-complex). Clin Neuropathol 4:181-199, 1985.

35. Powers JM, DeCiero DP, Ito M, Moser AB, Moser HW. Adrenomyeloneuropathy: a neuropathologic review featuring its noninflammatory myelopathy. J Neuropathol Exp Neurol 59:89-102, 2000.

36. Powers JM, DeCiero DP, Cox C, Richfield EK, Ito M, Moser AB, Moser HW. The dorsal root ganglia in adrenomyeloneuropathy: neuronal atrophy and abnormal mitochondria. J Neuropathol Exp Neurol 60:493-501, 2001.

37. van Geel BM, Koelman JH, Barth PG, Ongerboer de Visser BW. Peripheral nerve abnormalities in adrenomyeloneuropathy: a clinical and electrodiagnostic study. Neurology 46:112-118, 1996.

38. Kumar AJ, Kohler W, Kruse B, Naidu S, Bergin A, Edwin D, Moser HW. MR findings in adult-onset adrenoleukodystrophy. AJNR Am J Neuroradiol 16:1227-1237, 1995.

39. Dubey P, Fatemi A, Barker PB, Degaonkar M, Troeger M, Zackowski K, Bastian A, Smith SA, Pomper MG, Moser HW, Raymond GV. Spectroscopic evidence of cerebral axonopathy in patients with "pure" adrenomyeloneuropathy. Neurology 64:304$310,2005$.

40. Fatemi A, Smith SA, Dubey P, Zackowski KM, Bastian AJ, van Zijl PC, Moser HW, Raymond GV, Golay X. Magnetization transfer MRI demonstrates spinal cord pathology in adrenomyeloneuropathy. Neurology 1739-1745, 2005.

41. Smith KD, Kemp S, Braiterman LT, Lu JF, Wei HM, Geraghty M, Stetten G, Bergin JS, Pevsner J, Watkins PA. X-linked adrenoleukodystrophy: genes, mutations, and phenotypes. Neurochem Res 24:521-535, 1999.

42. van Geel BM, Bezman L, Loes DJ, Moser HW, Raymond GV. Evolution of phenotypes in adult male patients with X-linked adrenoleukodystrophy. Ann Neurol 49:186-94, 2001.

43. Aubourg P, Chaussain JL. Adrenoleukodystrophy: The most frequent genetic cause of Addison's disease. Horm Res 59:104-105, 2003.

44. Jorge P, Quelhas D, Oliveira P, Pinto R, Nogueira A. X-linked adrenoleukodystrophy in patients with idiopathic Addison disease. Eur J Pediatr 153:594-7, 1994.

45. Dubey P, Raymond G, Moser AB, Kharkar S, Bezman L, Moser HW. Adrenal insufficiency in asymptomatic adrenoleukodystrophy patients identified by very long chain fatty acid screening. $J \mathrm{Pe}$ diatr 146:528-532, 2005.
46. Eichler FS, Barker PB, Cox C, Edwin D, Ulug AM, Moser HW, Raymond GV. Proton MR spectroscopic imaging predicts lesion progression on MRI in X- linked adrenoleukodystrophy. Neurology 58:901-907, 2002.

47. Restuccia D, Di Lazzaro V, Valeriani M, Oliviero A, Le Pera D, Colosimo C, Burdi N, Cappa M, Bertini E, Di Biase A, Tonali P. Neurophysiological abnormalities in adrenoleukodystrophy carriers. Evidence of different degrees of central nervous system involvement. Brain 120 (Pt 7):1139-1148, 1997.

48. Fatemi A, Barker PB, Ulug AM, Nagae-Poetscher LM, Beauchamp NJ, Moser AB, Raymond GV, Moser HW, Naidu S. MRI and proton MRSI in women heterozygous for X-linked adrenoleukodystrophy. Neurology 60:1301-1307, 2003.

49. Hershkovitz E, Narkis G, Shorer Z, Moser AB, Watkins PA, Moser HW, Manor E. Cerebral X-linked adrenoleukodystrophy in a girl with Xq27-Ter deletion. Ann Neurol 52:234-237, 2002.

50. Naidu S, Washington C, Thirumalai S, Smith KD, Moser HW, Watkins PA. X-chromosome inactivation in symptomatic heterozygotes of X-linked adrenoleukodystrophy. Ann Neurol 42: 498a, 1997.

51. Maier EM, Kammerer S, Muntau AC, Wichers M, Braun A, Roscher AA. Symptoms in carriers of adrenoleukodystrophy relate to skewed X inactivation. Ann Neurol 52:683-688, 2002.

52. Kemp S, Wei HM, Lu JF, Braiterman LT, McGuinness MC, Moser AB, Watkins PA, Smith KD. Gene redundancy and pharmacological gene therapy: implications for X- linked adrenoleukodystrophy. Nat Med 4:1261-1268, 1998.

53. McGovern MM, Wasserstein MP, Aron A, Perrine SP. Biochemical effect of intravenous arginine butyrate in X-linked adrenoleukodystrophy. J Pediatr 142:709-13, 2003.

54. Pai GS, Khan M, Barbosa E, Key LL, Craver JR, Cure JK, Betros $\mathrm{R}$, Singh I. Lovastatin therapy for X-linked adrenoleukodystrophy: clinical and biochemical observations on 12 patients. Mol Genet Metab 69:312-322, 2000.

55. Fourcade S, Savary S, Gondcaille C, Berger J, Netik A, Cadepond F, El Etr M, Molzer B, Bugaut M. Thyroid hormone induction of the adrenoleukodystrophy-related gene (ABCD2). Mol Pharmacol 63:1296-1303, 2003.

56. Benhamida S, Pflumio F, Dubart-Kupperschmitt A, Zhao-Emonet JC, Cavazzana-Calvo M, Rocchiccioli F, Fichelson S, Aubourg P, Charneau P, Cartier N. Transduced CD34+ cells from adrenoleukodystrophy patients with HIV-derived vector mediate long-term engraftment of NOD/SCID mice. Mol Ther 7:317-324, 2003.

57. Zhang LX, Bakshi R, Fine E, Moser HW. Clinical and electrophysiological improvement of adrenomyeloneuropathy with steroid treatment. J Neurol Neurosurg Psychiatry 74:822-823, 2003.

58. Rizzo WB, Leshner RT, Odone A, Dammann AL, Craft DA, Jensen ME, Jennings SS, Davis S, Jaitly R, Sgro JA. Dietary erucic acid therapy for X-linked adrenoleukodystrophy. Neurology 39: 1415-1422, 1989.

59. van Geel BM, Assies J, Haverkort EB, Koelman JH, Verbeeten B $\mathrm{Jr}$, Wanders RJ, Barth PG. Progression of abnormalities in adrenomyeloneuropathy and neurologically asymptomatic X-linked adrenoleukodystrophy despite treatment with "Lorenzo's oil". J Neurol Neurosurg Psychiatry 67:290-299, 1999.

60. Uziel G, Bertini E, Bardelli P, Rimoldi M, Gambetti M. Experience on therapy of adrenoleukodystrophy and adrenomyeloneuropathy. Dev Neurosci 13:274-279, 1991.

61. Aubourg P, Adamsbaum C, Lavallard-Rousseau MC, Rocchiccioli F, Cartier N, Jambaque I, Jakobezak C, Lemaitre A, Boureau F, Wolf C, et al. A two-year trial of oleic and erucic acids ("Lorenzo's oil") as treatment for adrenomyeloneuropathy. $N$ Engl J Med 329: 745-752, 1993.

62. Rizzo WB, Leshner RT, Odone A, Craft DA, Jennings SS, Jaitly $\mathrm{R}$, et al. X-linked adrenoleukodystrophy: Biochemical and clinical efficacy of dietary erucic acid therapy, in Uziel G, Wanders RJA, Cappa ME (eds): Adrenoleukodystrophy and Other Peroxisomal Disorders. Amsterdam, Excerpta Medica, 1990, pp. $149-162$

63. Koehler W, Sokolowski P. Clinical phenotypes, diagnosis and treatment of adulthood X-linked adrenoleukodystrophy, in Berger J, Stoeckler S, Koehler W (eds): Understanding and Treating Adrenoleukodystrophy: 
Present State and Future Perspectives. SPS Verlagsgeseltschaft, Verlag Heilbronn, 2005, pp. 28-60.

64. Peters C, Charnas LR, Tan Y, Ziegler RS, Shapiro EG, DeFor T, Grewal SS, Orchard PJ, Abel SL, Goldman AI, Ramsay NK, Dusenbery KE, Loes DJ, Lockman LA, Kato S, Aubourg PR, Moser HW, Krivit W. Cerebral X-linked adrenoleukodystrophy: The international hematopoietic cell transplantation experience from 1982 to 1999. Blood 104:881-888, 2004.

65. Aubourg P, Blanche S, Jambaque I, Rocchiccioli F, Kalifa G, Naud-Saudreau C, Rolland MO, Debre M, Chaussain JL, Griscelli $\mathrm{C}$, et al. Reversal of early neurologic and neuroradiologic manifestations of X- linked adrenoleukodystrophy by bone marrow transplantation. N Engl J Med 322:1860-1866, 1990.

66. Shapiro E, Krivit W, Lockman L, Jambaque I, Peters C, Cowan M, Harris R, Blanche S, Bordigoni P, Loes D, Ziegler R, Crittenden M, Ris D, Berg B, Cox C, Moser H, Fischer A, Aubourg P. Long-term effect of bonemarrow transplantation for childhood-onset cerebral X-linked adrenoleukodystrophy. Lancet 356:713-718, 2000.
67. Hickey WF, Kimura H. Perivascular microglial cells of the CNS are bone marrow-derived and present antigen in vivo. Science 239:290-292, 1988

68. Unger ER, Sung JH, Manivel JC, Chenggis ML, Blazar BR, Krivit W. Male donor-derived cells in the brains of female sex-mismatched bone marrow transplant recipients: a Y-chromosome specific in situ hybridization study. J Neuropathol Exp Neurol 52: 460-470, 1993.

69. Nowaczyk MJ, Saunders EF, Tein I, Blaser SI, Clarke JT. Immunoablation does not delay the neurologic progression of X-linked adrenoleukodystrophy. J Pediatr 131:453-455, 1997.

70. Mahmood A, Dubey P, Raymond GV, Moser HW. Evaluating survival in nontransplanted boys with cerebral phenotype of Xlinked adrenoleukodystrophy. Ann Neurol in press, 2005.

71. Maier EM, Roscher AA, Kammerer S, Mehnert K, Conzelmann E, Holzinger A. Prenatal diagnosis of X-linked adrenoleukodystrophy combining biochemical, immunocytochemical and DNA analyses. Prenat Diagn 19:364-8, 1999. 